\title{
Radiation dose assessment for occupationally exposed workers in Malawi
}

\section{Getrude Chinangwa ${ }^{1}$, Joseph K. Amoako², John J. Fletcher ${ }^{3}$ \\ 1. Graduate School of Nuclear and Allied Sciences, University of Ghana, Accra, Ghana \\ 2. Radiation Protection Institute, Ghana Atomic Energy Commission, Accra, Ghana \\ 3. Department of Nuclear Sciences and Applications, University of Ghana, Accra, Ghana}

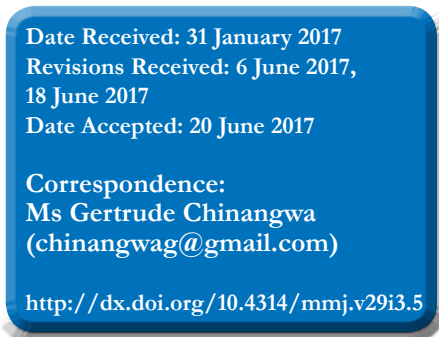

\section{Background}

\section{Abstract}

The objective of this study was to assess individual doses received by radiographers, and the scattered radiation dose rate reaching the control panel in X-ray departments of three hospitals in Malawi, in-order to compare them against the internationally recommended limits.

Methods

Themoluminescent Dosimeters were issued to fifteen (15) radiographers to record their dose for a month. Dose rate measurements were recorded using survey meters.

Results

Average monthly dose for workers was $0.247 \mathrm{mSv}$. Average ambient dose rate values were $0.39 \mu \mathrm{Sv} / \mathrm{hr}$ for Mtengo wa Nthenga Hospital, $5.03 \mu \mathrm{Sv} / \mathrm{hr}$ for Bwaila Hospital and $4 \mu \mathrm{Sv} / \mathrm{hr}$ for Kamuzu Central Hospital.

Conclusions

Dose levels are below the limits recommended by the International Commission on Radiological Protection (ICRP).

\section{Introduction}

Diagnostic radiology is the major practice involving ionising radiation in Malawi. The Country became an International Atomic Energy Agency (IAEA) member state in 2006 and developed the Atomic Energy Act and Regulations in 2011 and 2012, respectively. ${ }^{1}$ However, the regulatory authority, which ensures that users of ionising radiation comply with the legislation and safety requirements, has not yet been established. In 2012, IAEA provided Malawi with the Harshaw 4500 Manual Themoluminescent dosimeters (TLD) Reader to support the country in establishing the personnel dosimetry service. The service is however not yet in operation because some infrastructural and operational arrangements have not yet been instituted. This situation therefore brings uncertainty on workers' safety and potential occupational exposure to ionising radiation such as X-rays. This study was hence conducted with the aim of finding out the radiation dose levels currently being received by occupationally exposed workers in radiology departments and compare them against the International Commission on Radiological Protection (ICRP) recommended limits shown below:

Table 1: Occupational exposure limits (ICRP 75, 1997) ${ }^{2}$

\begin{tabular}{ll}
\hline Application & Dose limits \\
\hline & $50 \mathrm{mSv}$ per year (or $1 \mathrm{mSv}$ per week) \\
Effective dose (whole body), Hp (10) & $20 \mathrm{mSv}$ per year (or $0.4 \mathrm{mSv}$ per week) averaged over \\
defined periods of five years
\end{tabular}

Annual equivalent dose to lens of the eye, $\mathrm{Hp} \mathrm{(3)} 150 \mathrm{mSv}$

Annual equivalent dose to the skin, $\mathrm{Hp}(0.07) \quad 500 \mathrm{mSv}$

Annual equivalent dose to hands and feet

$500 \mathrm{mSv}$
Exposure to ionising radiation has two main effects to human beings, these are: deterministic effects and stochastic effects. Deterministic effects are those effects for which generally a threshold level of dose exists above which the severity of the effect is greater for a higher dose. Examples include: acute radiation syndrome (ARS), skin burns, sterility and cataract. These effects are mainly associated with exposure to high radiation doses for a short time (acute exposure). ${ }^{3}$ On the other hand, stochastic effects are the effects, generally occurring without a threshold level of dose, but their probability of occurrence is proportional to the dose and their severity is independent of the dose. Radiation induced cancer and some hereditary effects are main examples of stochastic effects. These effects are associated with exposure to low radiation doses for consistent long time (chronic exposure).

For every practice that involves the use of ionizing radiation, it is important for protection to be optimized. Optimization simply means the process of making sure that the number of individuals subject to exposure, the likelihood of exposure and the magnitude of exposure are kept as low as reasonably achievable (ALARA). ${ }^{4}$ Optimization is key to achieving the aim of radiation protection which is to prevent deterministic effects and reduce the probability of stochastic effects. Dose assessment is crucial in achieving the dose limitation principle of radiation protection. In the process of achieving the objective of radiation protection, it is important to monitor the doses received by exposed individuals so as to make sure that they are within recommended limits. In this study, the practice of ALARA and dose limitation principles were assessed in some hospitals in Malawi. 


\section{Methods}

Prior to data collection, ethical clearance and approval was sought from the Ministry of Health, hospitals involved and the National Health Sciences Research Committee. Three hospitals were selected for the study according to three levels of health care service delivery in Malawi (i.e. regional level, district level and community level). Kamuzu Central Hospital $(\mathrm{KCH})$ was chosen as a regional hospital, Bwaila Hospital as a district hospital and Mtengo wa Nthenga Hospital as a community hospital. A total of fifteen (15) radiographers from these hospitals voluntarily participated in the study. Due to funds and time limitations, only three hospitals were selected for this study, depending on the functionality of X-ray machines and the number of radiographers in their X-ray departments. However, this limitation did not compromise the study objective and results because the sample size was maintained (that is, 15 radiographers).

\section{Individual monitoring}

Nineteen (19) Themoluminescent dosimeters (TLDs) from Radiation Protection Institute of Ghana Atomic Energy Commission (GAEC) were used to record individual doses for radiographers for one-month period. Fifteen of them were issued to radiographers, three were used as control cards for each hospital and one was used to record dose in transit. Background dose recorded by control cards was subtracted from personal dosimeters' readings to give true dose for each worker.

\section{Workplace monitoring}

A workplace monitoring was carried out to obtain radiation safety information of radiographers' working areas. Two calibrated Rados Multi-Purpose Survey Meters were used to measure the scattered radiation dose rate $\left[\mathrm{H}^{*}(10)\right]$ in X-ray control panels. Ambient dose equivalent, $\mathrm{H}^{*}(\mathrm{~d})$, at a point in a radiation field is defined as the dose equivalent that would be produced by the corresponding field in the ICRU sphere at a depth $\mathrm{d} \mathrm{mm}$. This quantity is mostly used to assess doses from strongly penetrating radiations such as gamma and X-rays at the recommended depth of $10 \mathrm{~mm}$ of the ICRU sphere. It gives a reasonable approximation to the effective dose.

\section{Data analysis}

Individual doses were analysed in the Windows Radiation Evaluation and Management System (WinREMS) embedded in the Harshaw 6600 Automated TLD Reader located at Radiation Protection Institute, GAEC. Microsoft Excel was used to analyse workplace monitoring records.

\section{Results}

Descriptive statistics of whole body and skin dosimetry readings are shown in Table 2 and Table 3, respectively. Figure 1 (whole body measurements) and Figure 2 (skin measurements) illustrate the individual radiation dosimetry measurements among the participants. Figure 3 shows the average daily radiation dose emitted at each facility.

Table 2: Statistics of staff (whole body) radiation doses

\begin{tabular}{lcccc}
\hline Statistics & Minimum & Maximum & Mean & $\begin{array}{c}\text { Standard } \\
\text { deviation }\end{array}$ \\
\hline $\begin{array}{l}\text { Hp (10) } \mathbf{~ m S v / ~} \\
\text { month }\end{array}$ & 0.069 & 0.749 & 0.247 & 0.178 \\
\hline
\end{tabular}

Figures 4 to 6 depict the floor plans of the facilities involved in this study.

'Table 3: Statistics of staff skin radiation doses

\begin{tabular}{lcccc}
\hline Statistics & Minimum & Maximum & Mean & $\begin{array}{l}\text { Standard } \\
\text { deviation }\end{array}$ \\
\hline $\begin{array}{l}\text { Hp (0.07) } \\
\text { mSv/month }\end{array}$ & 0.236 & 1.074 & 0.411 & 0.272 \\
\hline
\end{tabular}

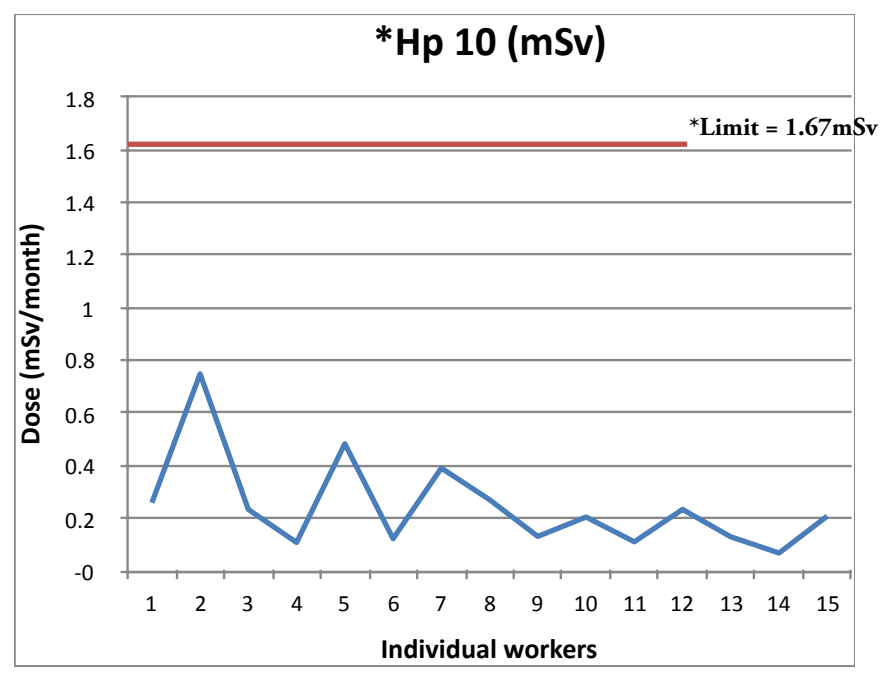

Figure 1: Individual whole body radiation measurements ${ }^{*} \mathrm{Hp}(10)=$ effective dose equivalent; ${ }^{*}$ The monthly limit was found by dividing annual limit $(20 \mathrm{mSv})$ by number of months per year (12)

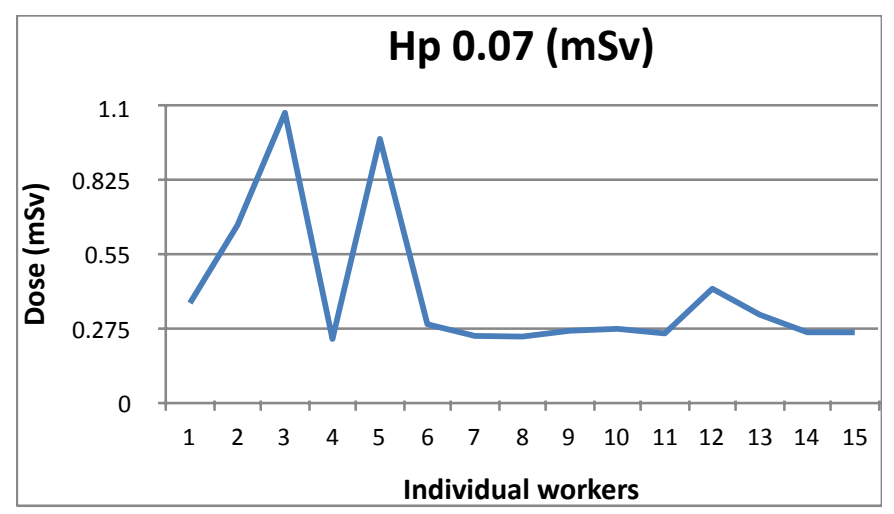

Figure 2: Individual skin radiation measurements [ $\mathrm{Hp} \mathrm{(0.07)]}$ For the skin dose, $\mathrm{Hp}(0.07)$, the readings were also below the International Commission on Radiological Protection (ICRP) monthly limit of $41.67 \mathrm{mSv}$ (found by dividing the annual limit of $500 \mathrm{mSv}$ by 12 months)

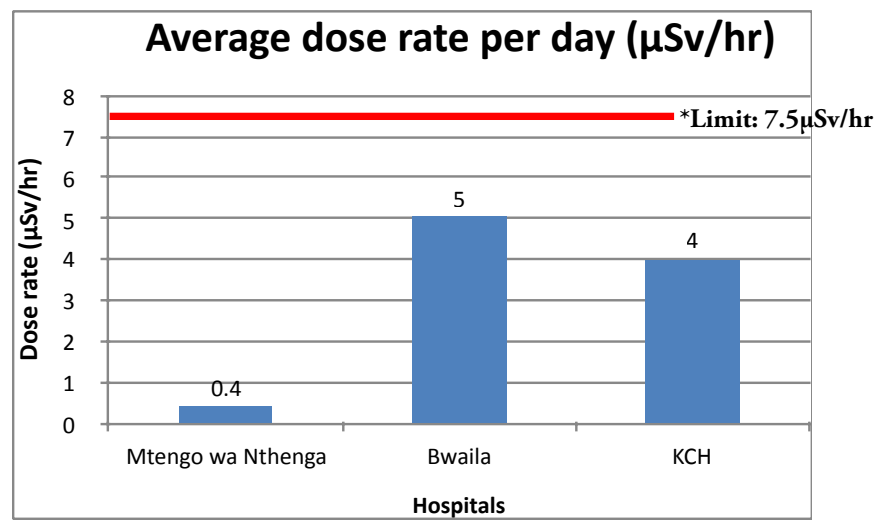

Figure 3: Average ambient radiation dose rate per day

*The ICRP 1997 set an annual dose limit of $50 \mathrm{mSv}$ in one year for radiation workers (see Table 1). Any worker who exceeds $3 / 10$ of this limit is designated a "classified" radiation worker; i.e, $50 \mathrm{mSv} / \mathrm{yr}=1 \mathrm{mSv} / \mathrm{week}=25 \mu \mathrm{Sv} / \mathrm{hr}$ (for a 40 hour working week); $3 / 10$ of this limit $=25 \times 3 / 10=7.5 \mu \mathrm{Sv} /$ hour $=$ the adequate shielding level/limit 


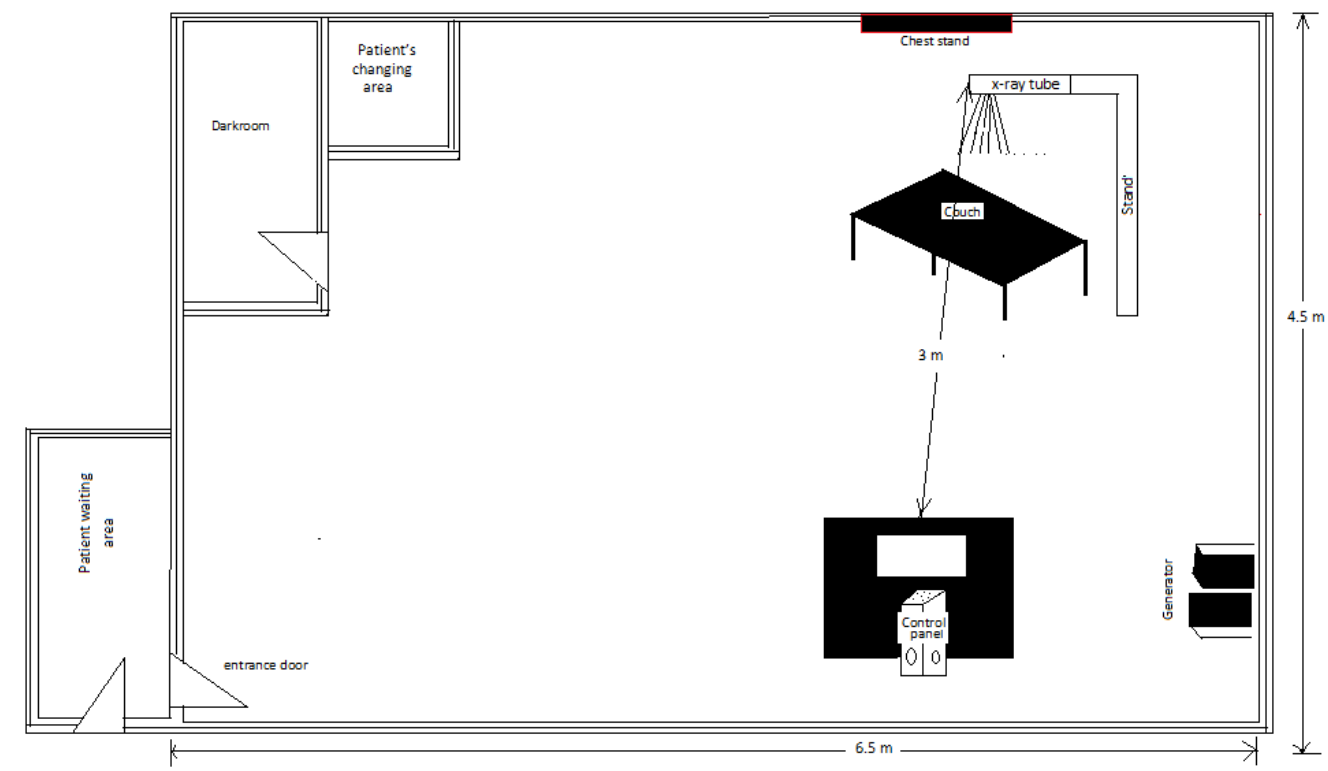

Figure 4: Mtengo wa Nthenga $x$-ray room layout

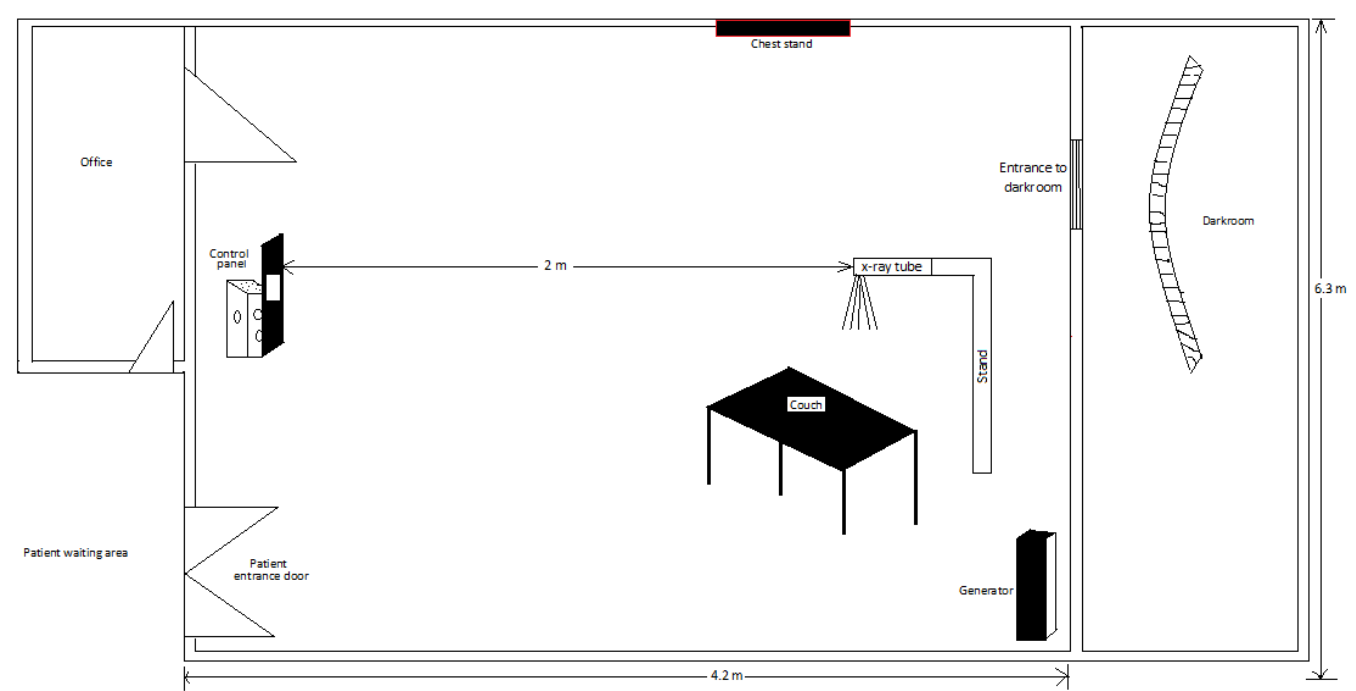

Figure 5: Bwaila x-ray room layout

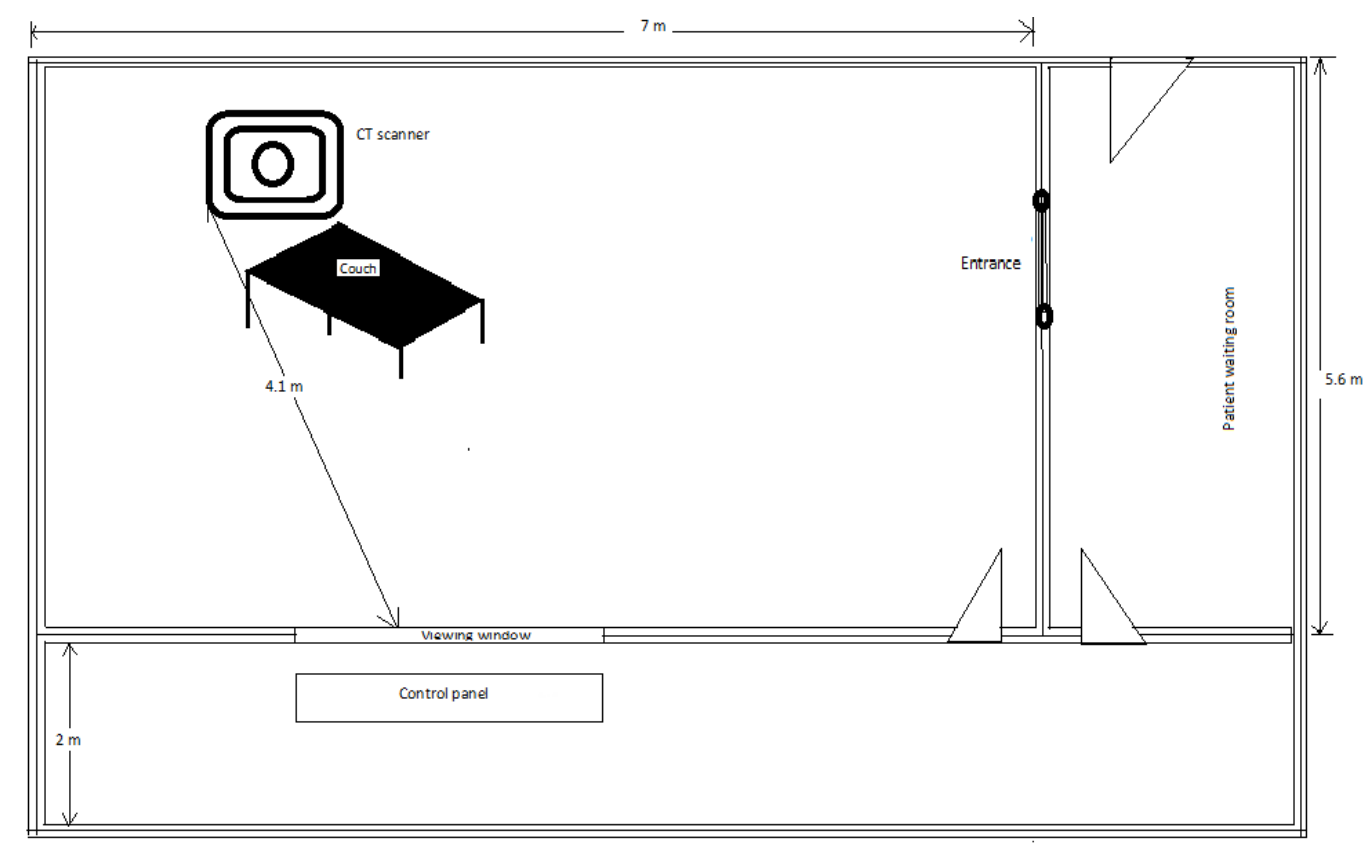

Figure 6: Kamuzu Central Hospital computed tomography (CT) room layout 


\section{Discussion}

It was observed that dose values for individual and workplace monitoring are not exactly the same. However, their pattern or trend is similar. For example, Bwaila hospital had highest values both in ambient dose rate as well as the individual dose. On the other hand, Mtengo wa Nthenga had low values in both monitoring methods. Another observation was that $\mathrm{KCH}$ had low individual dose values despite the high workload and long exposure time associated with the CT scanner. Reasons could be; workers are not constantly in the CT control room at the same time and because the CT control room was designed to reduce occupational exposure. It was observed that in their work schedule, there is staff rotation which implies that the CT control room is shared to different individuals. The operator at the CT machine is not the same individual all the time. On other days, the radiographers operate ultrasound machines (without ionizing radiation), conventional $\mathrm{X}$-ray machines or mobile $\mathrm{X}$-ray machines (C-arms) which generally have low exposure rates. At Bwaila, there were two workers constantly working with one general X-ray machine and high number of patients per day. As such, the two workers were obtaining diagnostic images for a longer time than other facilities.

A similar study was conducted in Montenegro in 20079. Montenegro is a small, developing and "non-nuclear" country in Europe. At a time of the study, there was neither a regulatory authority for radiation protection in the country nor a source register. The application of radiation sources was limited mostly to medicine. The study was also performed in medical institutions and the aim was to compare the results against the internationally recommended limits. It was found that the average equivalent dose for one month period was $0.0703 \mathrm{mSv}$ for physicians and $0.0827 \mathrm{mSv}$ for technicians. The highest dose recorded in one month was $1.1 \mathrm{mSv}$ for a technician in Niksic Hospital. The study concluded that the doses were well below internationally recommended limits for all subjects monitored.

Nepal, is a country located in South Asia whose situation is similar to that of Malawi. It became a member of the IAEA in 2007. Nepal has a long history of medical radiology since 1923 but unfortunately, by 2012 the country still did not have any Radiation Protection Infrastructure to control the use of ionizing radiation in the various fields. In 2012, a study, whose objective was to assess the radiation protection in medical uses of ionizing radiation, was conducted. Twentyeight hospitals with diagnostic radiology facilities were chosen for the study and radiation surveys were also done at five different radiotherapy centres. A questionnaire was administered to occupationally exposed workers, radiation dose levels were measured and an inventory of radiation equipment was made. The study also aimed at creating awareness among workers on possible radiation health hazard and risk. It was also deemed important to know the level of understanding of the radiation workers in order to initiate steps towards the establishment of Nepalese laws, regulation and code of radiological practice in this field. It was found that radiation dose levels at the reference points for all the five radiotherapy centres were within safe limits. Around $65 \%$ of the radiation workers had never been monitored for radiation. The study found out also that there was no quality control program in any of the surveyed hospitals except in radiotherapy facilities. ${ }^{10}$
Table 4: Comparision of individual dose results in different countries $^{5-8}$

\begin{tabular}{lccc}
\hline Country & Year of study & $\begin{array}{c}\text { Average monthly } \\
\text { radiation dose } \\
(\mathbf{m S v})\end{array}$ & $\begin{array}{c}\text { Average annual } \\
\text { radiation dose } \\
(\mathbf{m S v})\end{array}$ \\
\hline Kenya & $2002-2005$ & 0.24 & 2.94 \\
Mexico & 2004 & 0.24 & 2.9 \\
Kuwait & $2008-2009$ & 0.0875 & 1.05 \\
Ghana & $2000-2009$ & 0.0875 & 1.05 \\
Malawi (this study) & 2016 & 0.247 & $2.964^{*}$
\end{tabular}

*Projected

Other similar studies were conducted in Kenya, Mexico, Kuwait and Ghana with the purpose of comparing the individual doses against the recommended limits. Table 4 above, presents the individual monitoring findings from such studies in comparison with the findings from this study. The results from individual monitoring carried out in this study for Malawi are not much different from the findings from the other studies.

\section{Conclusions}

Ambient dose rate and individual doses were below the recommended ICRP limits. The study recommends that personnel dosimetry service in Malawi should start operating so that occupationally exposed workers in hospitals and other non-medical industries can be consistently monitored. The study also recommends quality control tests for X-ray machines and structural shielding assessment in these hospitals and all radiology facilities in Malawi.

\section{Acknowledgements}

The support received from the following institutions is very much appreciated: International Atomic Energy Agency, Department of Radiography in the Ministry of Health; National Health Sciences Research Committee; Management and Staff of Kamuzu Central Hospital, Bwaila Hospital and Mtengo wa Nthenga Hospital; Environmental Affairs Department, Malawi Bureau of Standards and Radiation Protection Institute of Ghana Atomic Energy Commission.

\section{Competing interests}

All authors declare that they have no competing interests related to this work.

\section{References}

1. Malawi Government, Atomic Energy Act; 2011.

2. The International Commission on Radiological Protection; General Principles for the Radiation Protection of Workers, ICRP Publication $75 ; 1997$.

3. International Atomic Energy Agency., Radiation Protection Distance Learning Project, Module 1.6 - Biological Effects of Exposure to Ionizing Radiation, www.iaea.org.

4. International Atomic Energy Agency; 1999; Occupational Radiation Protection, Safety Guide No. RS-G-1.1, Vienna.

5. Kiti AS; Occupational Exposure to Ionising Radiation in Kenya; 2005.

6. Gaona E, Enriquez JGF; Occupational Exposure to Diagnostic Radiology in Workers Without Training in Radiation Safety; https:// www.researchgate.net/publication/234858034; 2004.

7. Al-Abdulsalam A, Brindhaban A; Occupational Radiation Exposure Among the Staff of Departments of Nuclear Medicine and Diagnostic Radiology in Kuwait, Department of Radiologic Sciences, Kuwait University; Med Princ Pract 2014; 23:129-133. 
8. Hasford, F, Owusu-Banahene J, Amoako JK, et al; Assessment of Annual Whole-body Occupational Radiation Exposure in Medical Practice in Ghana (2000-2009); Radiat Prot Dosimetry, 2012 May; 149(4): 431-7

9. Milatović, A. et al., 2008; A Dose Estimation for Persons Occupationally Exposed to Ionizing Radiation in Montenegro.
10. Adhikari, et al., Status of Radiation Protection at Different Hospitals in Nepal, Journal of Medical Physics; October-December 2012, Vol. 37 Issue 4, p240. 